\title{
THE POSSIBILITIES OF USING THE TERRESTRIAL SCANNING DATA FOR CLASSIFICATION OF ROCKS IN LIMESTONE MINE "CZATKOWICE"
}

\author{
Cezary Toś \\ Department of Land Surveying and Engineering Geology, \\ Cracow University of Technology, Cracow, Poland
}

\begin{abstract}
This paper presents results of a research of potential utilisation of the intensity of laser beam reflection recorded by ground-based lasers, for an initial classification of rock formations within the Czatkowice Limestone Quarry. As part of the research, spectrometric analysis in visible (VIS), near-infrared (NIR) and Short-wavelength infrared (SWIR) bands was carried out for rock samples typical for the Czatkowice Quarry. Moreover, the rock samples were scanned using equipment working within different wavelengths. The reflected intensity of the laser beam recorded for each rock sample with several different scanners were analysed to assess their potential use for rock classification. The results of this analysis were then compared with spectral curves of each sample. The relationship between the intensity of the laser beam reflection and the spectral curves can be used for selection of most suitable scanner for rock classification.
\end{abstract}

Keywords: Limestone Quarry, Laser scanning, Intensity, Classification.

\section{Introduction}

The open pit miming process requires regular surveys of the quarry wall face. The existing site data records can be used for effective quarry-mining operation and production planning as well as an initial assessment of quality and volumes of quarried material. However, the safety of site exploitation and land-use planning depends heavily on the quality of the available geotechnical records. The effectiveness of laser scanning for object geometry, including quarry assessment, is undisputable and well-researched (Maciaszek \& Ćwiąkała, 2010; Ratcliffe \& Myers, 2006; Toś et al. 2010). Terrestrial laser scanning (TLS) is not time-consuming and is carried out remotely. TLS allows to create an accurate 3D model of a quarry wall before and after blasting operation. These geometric data can be used to calculate the volume of excavated material. 
The composition of the quarry wall and therefore the quality of the quarry output is assessed through laboratory testing of numerous rock samples as well as geological in situ assessment. The aim of this study is to assess the potential use of laser scanning data for initial classification of limestone from the Czatkowice Limestone Quarry.

The data obtained by laser scanning includes point cloud, colour data recorded by built-in RGB camera and intensity of laser beam reflection (I). The RGB bands can be used for rock classification within the quarry wall. However, such classification, based solely on the visible bands from RGB camera, typically does not give expected results. The use of the intensity of laser beam reflection as spectral band is difficult, as it depends on several factors:

- $\quad$ surface characteristic, as has been shown in (Voegtle et al. 2006) (Toś, 2013)

- $\quad$ the angle of laser beam incidence on the surface, (Soudarissanane et al. 2005)

- $\quad$ scanning distance, (Hoefle \& Pfeifer, 2007)

- $\quad$ surface irregularities, etc (Pesci \& Teza, 2008)

- $\quad$ moisture of the objects surface (Franceschi et al. 2009),

Moreover, recorded intensity is often optimized only for visualisation purposes (Franceschi et al. 2009)

Despite these factors, I value contains information that can be used for rock classification. However, rock classification is possible only when significant reflectance coefficient variations occur. Therefore, this study compares scanning results obtained for various wavelength ranges with spectrometric observations.

\section{Research Objectives and Methodology}

The basis of this research was the spectrometric analysis of rock samples from the Czatkowice Limestone Quarry. Collected and classified samples were analysed using spectrometer FieldSpec $\mathrm{PRO}$, in a measuring $0.35 \div 2.50 \mu \mathrm{m}$ wavelength range. Spectrometric examination was performed in laboratory conditions. Figure 1 shows spectral curves for dry samples, studied at the natural fraction. The curves show the average for 15 measurements of reflectance coefficients at specific wavelengths.

The rock samples were also scanned using the following scanners:

- $\quad$ Topcon GLS 1500 - pulse-based scanner, wavelength 1535 nm (Shortwavelength infrared SWIR)

(http://www.topconpositioning.com/products/scanning/gls-1500),

- Faro - phase-based scanner, wavelength $905 \mathrm{~nm}$ (near-infrared NIR) (http://www2.faro.com/site/resources/s hare/944),

- $\quad$ Leica C10 - pulse-based scanner, wavelength $532 \mathrm{~nm}$ (Green in visible range) (http://www.laserscanning-europe.com/en/leica-laser-scanner-p15-c10-p20hds6100-hds4400).

The spectrometric analysis results demonstrate that within the rocks found in the Czatkowice Limestone Quarry:

- no significant differences exist in the coefficient of reflectance recorded for limestone, dolomitic limestone and silica limestone (samples 1/1, 3/2 and 4/2) (Figure1),

- bituminous limestone (samples $3 / 1$ and 4/1) have low coefficient of reflectance in the entire band of visible (VIS) and NIR range, therefore they can be easily separated, 
- limestone residual (samples 2/1 and 5) and calcite (k) can be separated by using suitable NIR and SWIR bands.

In addition, the spectral curves observed for the samples in Figure. 2, indicate the wavelength bands for which the reflectance coefficient vary. Scan data obtained from scanners operating in these wavelength bands is expected to give better classification results compare to other scanners.

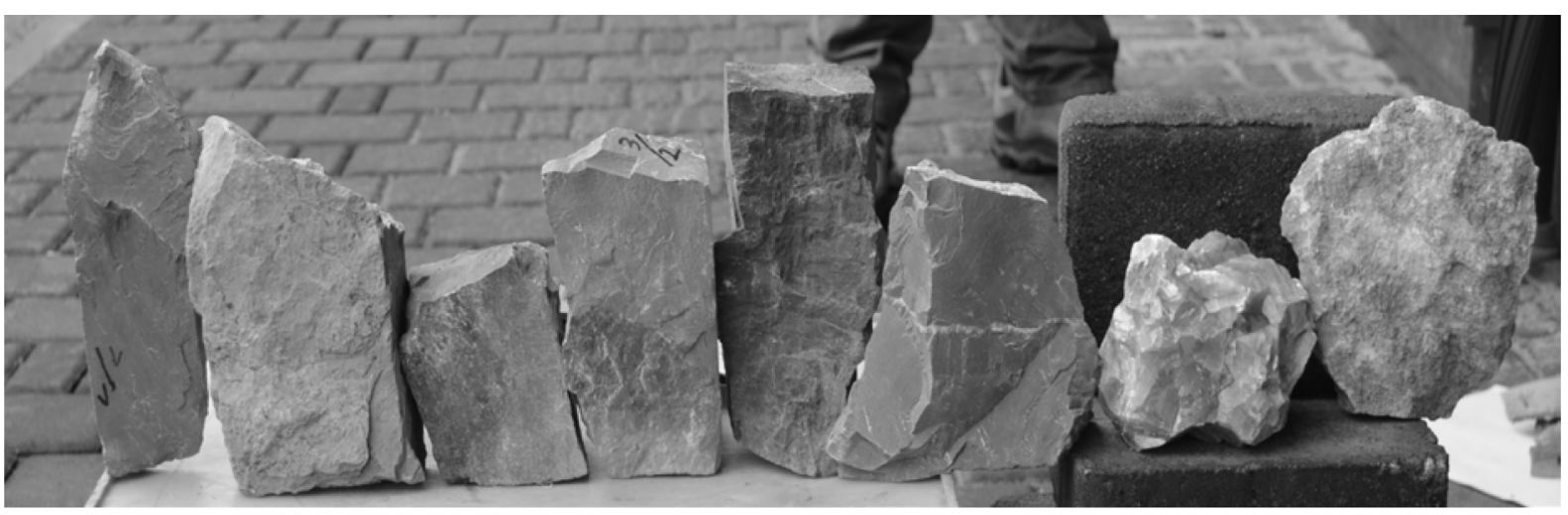

Fig. 1. Samples from the Czatkowice Limestone Quarry, from left: microcrystalline limestone (1/1), limestone residual (2/1), bituminous limestone (3/1), dolomitic limestone (3/2), bituminous limestone (4/1), silica limestone (4/2), Calcite (k), limestone residual (5).

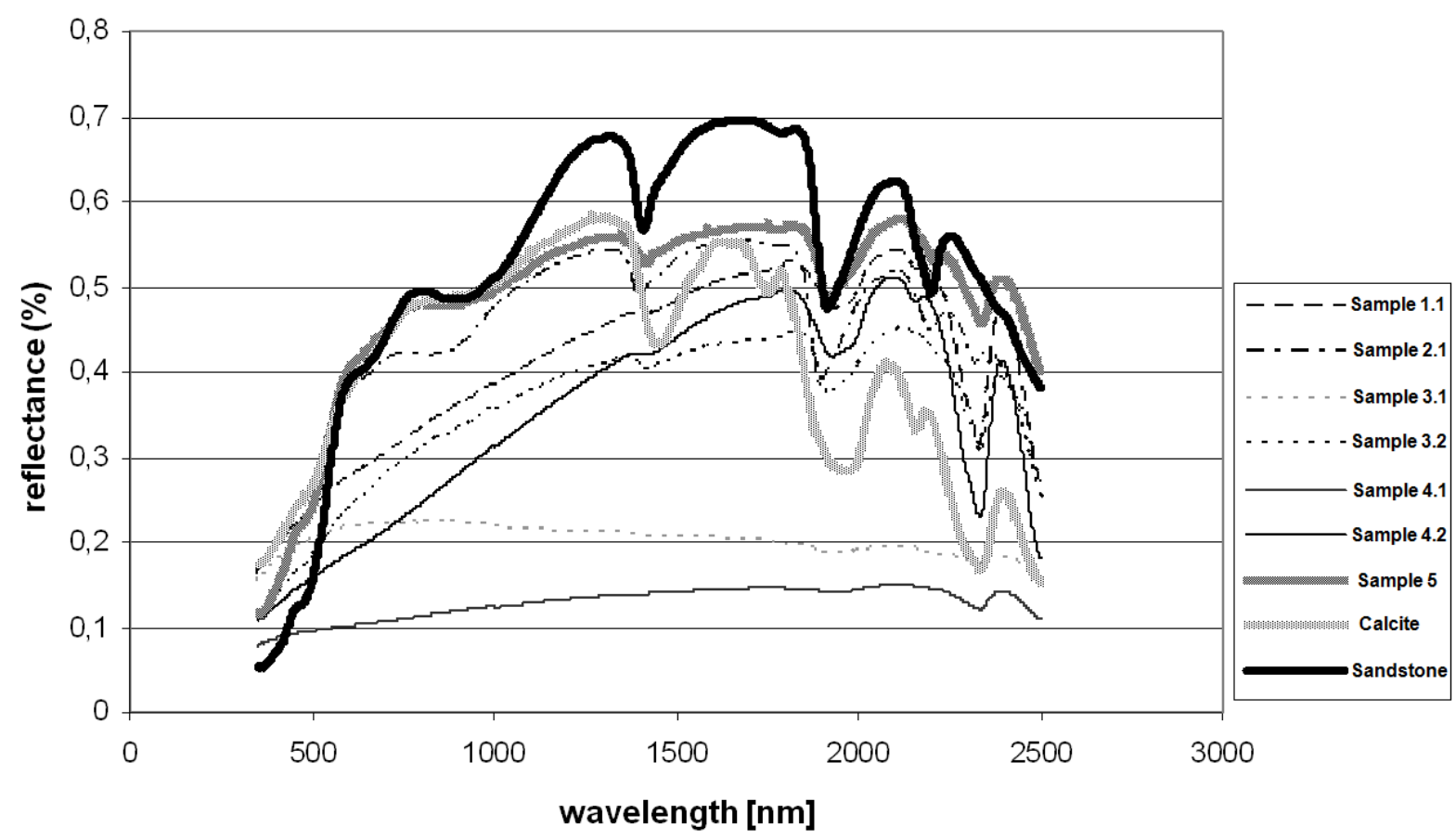

Fig. 2. Spectral curves of studied dry samples

To determine water influence on the spectral curves additional analyses of wet rock samples were carried out. Reflectance curves in Figure 3 show significant spectral instabilities due to water absorption bands. The spectral instabilities make the rock classification very difficult. The water influence on the reflectance coefficient is clearly related to the porosity of rock. For low-porosity rock (calcite), that effect is limited to strong water-related absorption peaks (1400-1600 nm) and (1800-2100). For high-porosity rock (sandstone), that effect is marked in the entire range (350$2500 \mathrm{~nm}$ ). 


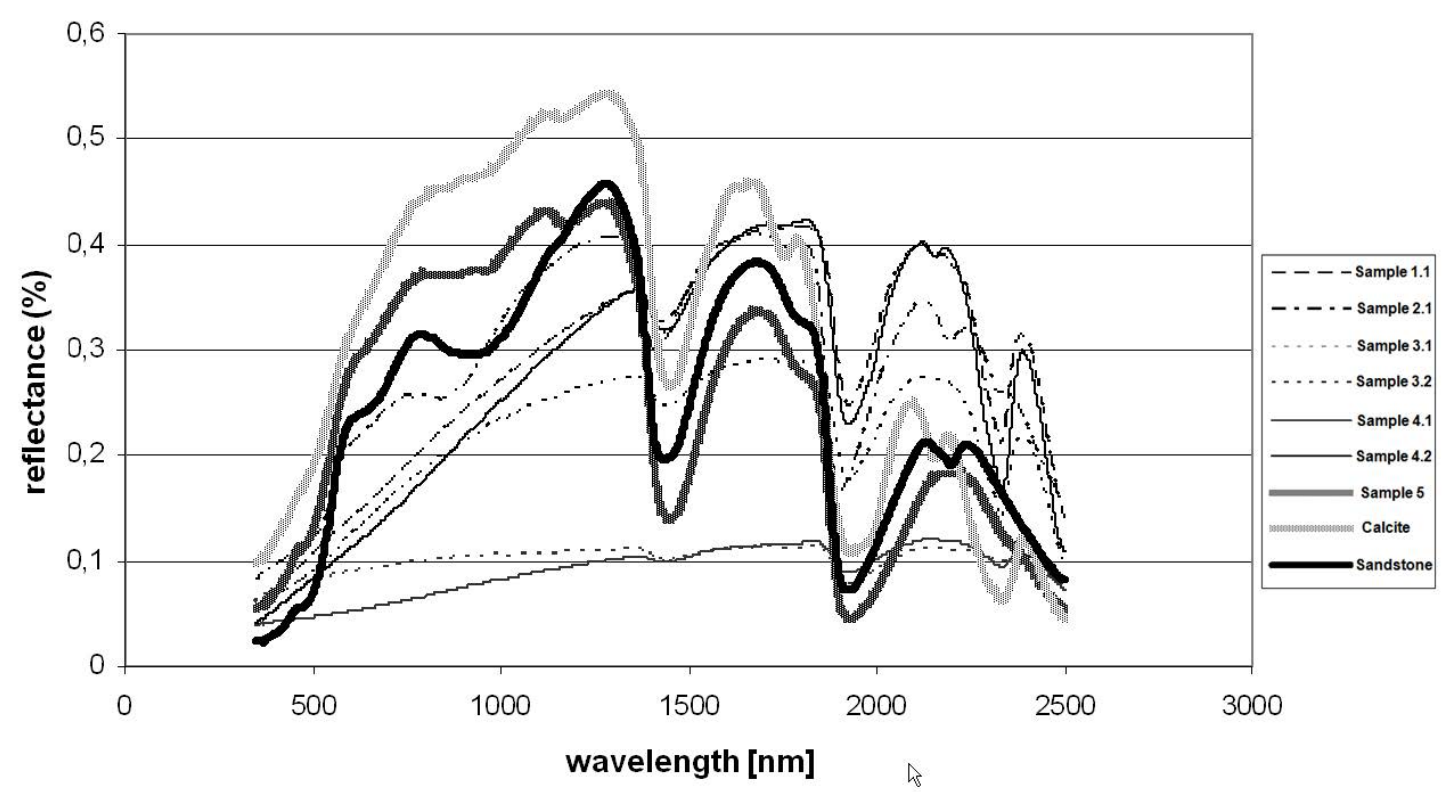

Fig. 3. Spectral curves of studied wet samples

As a result, eight dry samples were scanned form the distance of $30 \mathrm{~m}$ with resolution of about $4 \mathrm{~mm}$, using 3 types of scanners. Scan resolutions were the same as the smalest laser spot size in the scanners used. The samples with sizes ranging from $15 \times 20 \mathrm{~cm}$. to $25 \times 35 \mathrm{~cm}$. were placed with the natural surface positioned perpendicularly to the scanner to reduce the influence of beam incidence angle. From 1000 to 5000 points were recorded for each sample. Complete set of laser scanning data was recorded including point coordinates, colours RGB and intensity of the laser beam reflection $(I)$.

The data processing consisted of:

- compilation of intensity histograms and its comparison with spectral curves;

- $\quad$ identification of separability of pairwise of rock classes signatures for RGB and RGBI bands, which are crucial for accurate rock classification;

- completion of supervised classification of I, RGB and RGBI bands and assessment of its accuracy.

\section{Intensity values $(I)$ and Spectral Curves Comparison}

The scan data was used to produce laser beam intensity histograms for each rock sample. Due to different scan data formats, intensity values were calculated in relation to the minimum and maximum value recorded in point cloud (as shown in Żaczek-Peplińska \&. Falaciński, 2011). Figure 4 shows intensity histograms (I) recorded with TOPCON GLS 1500 scanner for each rock sample. 

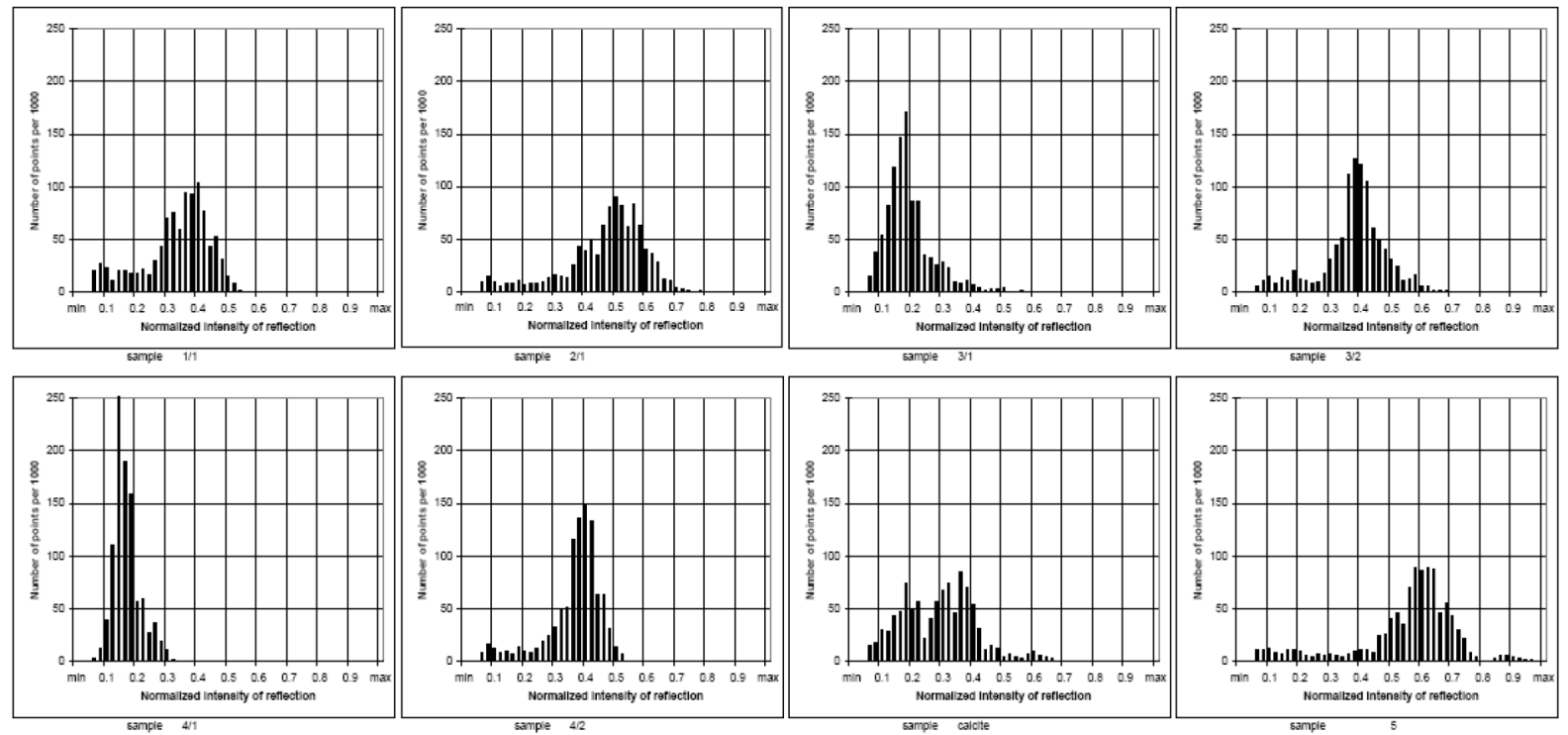

Fig. 4. Intensity histograms of all samples recorded with TOPCON GLS 1500.

The scan results are characterized by high variance which has a negative effect on the research. However, the high variance is partially due to influence of beam incidence angle, as most graphs are asymmetric. Standard deviation varies between:

- from 0.04 to 0.17 (entire range of intensity value) for Topcon,

- $\quad$ from 0.03 to 0.09 , for Faro,

- $\quad$ from 0.02 do 0.09 for Leica.

The I values recorded for each sample were compared with the spectrometric analysis results. Figure 5 show correlation between average values of the reflectance coefficient and the intensity $(I)$.
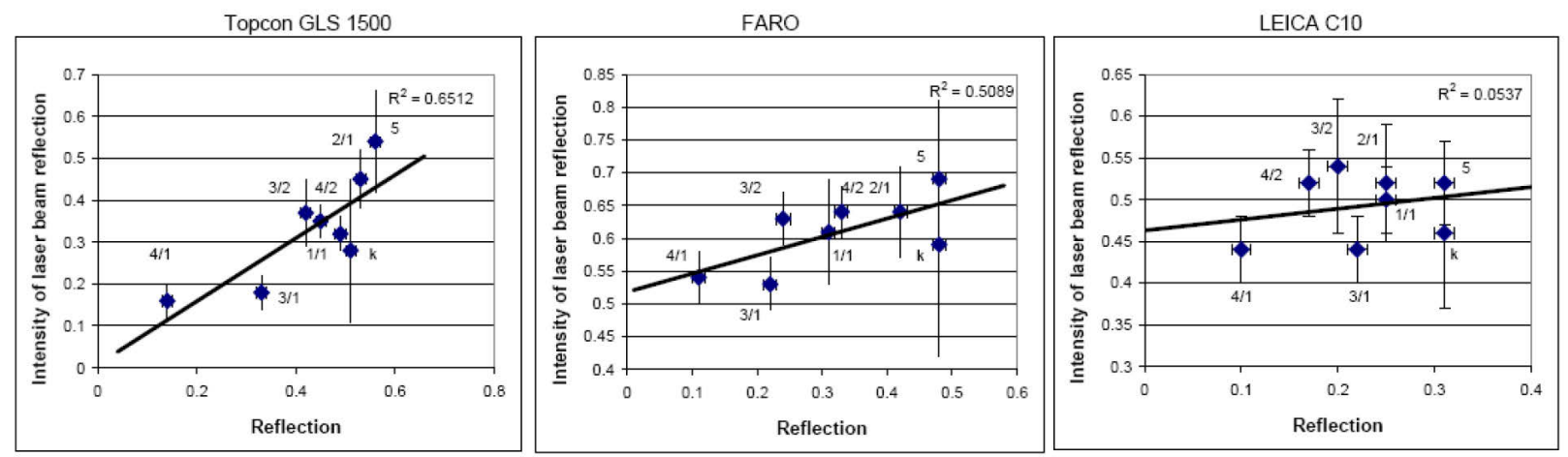

Fig. 5. Average values comparison of the reflectance coefficient and intensity of laser beam reflection.

This research demonstrates an important correlation of the spectral curves with the scan data obtained using GLS 1500 (coefficient of determination of 0.65). Calcite is an exception. Calcite is a coarse-grained rock, partially transparent, therefore causing a significant laser beam dispersion and refraction. The coefficient of determination of 0.51 for Faro scanner also indicates a significant correlation. The scan data obtained with $\mathrm{C} 10$ scanner is not correlated with the spectral curves. This is most likely due low differentiation of the reflectance coefficient for $532 \mathrm{~nm}$ wavelength as well as high variation of the $I$ value . 


\section{Separability Analysis of Rock-type Classes}

Separability of pairwise of class signatures was calculated using software originally developed for 2D image analysis. Therefore, it was necessary to convert point cloud into 2D image. Typical projective transformation could distort brightness interpolation of pixel value. Therefore, points were arranged in uniform grid (Figure 6). There was a simple transformation:

$$
\operatorname{Pont}(\text { No, } x, y, x, R, G, B, I) \rightarrow \operatorname{Piksel}(\text { Row, Kolumn, pixelvalue) }
$$

where row and column was computed from the point number (No) and size of a new image, and pixel value was equal to one of R,G,B or I value.
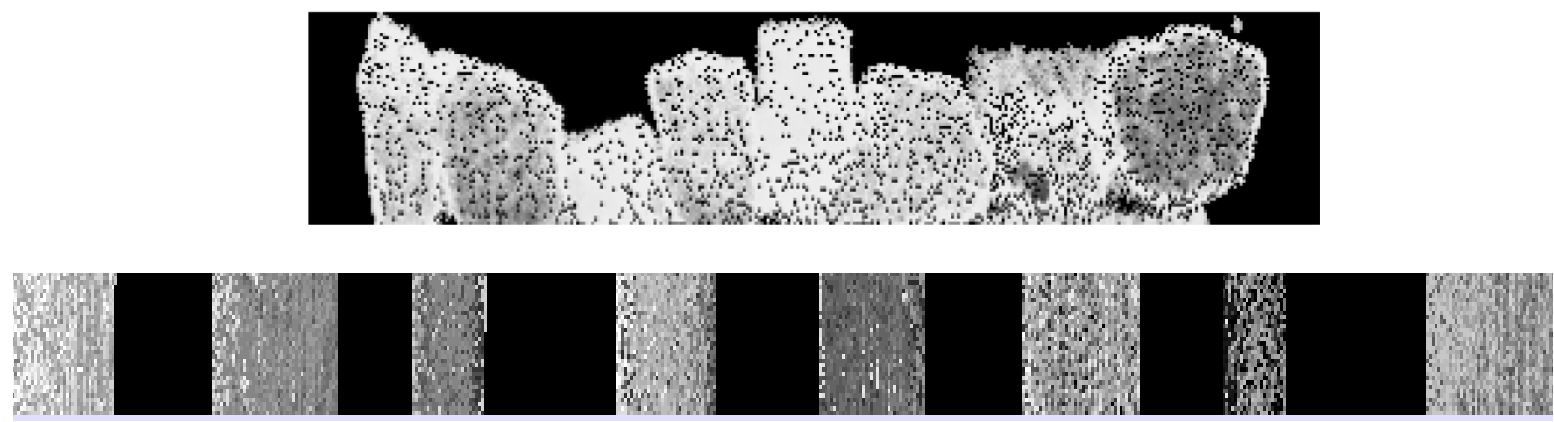

Fig. 6.Laser beam reflection intensity images; original and converted

Eight classes corresponding with the particular sample were identified on the prepared specimen images. For all pairwise classes, transformed divergence (TD) was calculated as a separability measure (Richards, 1993) for RGB and RGBI bands. Transformed divergence calculated using formula (2) scores from 0 to 2000. Transformed divergence scores in excess of 1600 indicate good separability (Richards, 1993).

$$
T D_{i j}=2000 \cdot\left(1-e^{\frac{-d_{i j}}{8}}\right)
$$

where: $d_{i j}=0.5 \cdot \operatorname{tr}\left\{\left(C_{i}-C_{j}\right)\left(C_{i}^{-1}-C_{j}^{-1}\right)\right\}+0.5 \cdot \operatorname{tr}\left\{\left(C_{i}^{-1}-C_{j}^{-1}\right)\left(m_{i}-m_{j}\right)\left(m_{i}-m_{j}\right)^{-1}\right\}, C$ is the covariance matrix and $m$ is the vector of mean values.

Table 1. Average Transformed Divergence values for RGB and RGBI bands.

\begin{tabular}{|c|c|c|c|}
\hline Bands Scanner & GLS 1500 & FARO & C10 \\
\hline RGB & 1391 & 1662 & 1362 \\
\hline RGBI & 1691 & 1881 & 1506 \\
\hline
\end{tabular}

The TD values shown in Table 1, indicates that the introduction of intensity of laser beam reflection band improves separability of pairwise class for all scanners. As expected, scanner operating in green band provides the poorest results. Scanner FARO with laser in NIR band and scanner GLS1500 with laser in SWIR band have better capabilities of rock classification in the Czatkowice Limestone Quarry. Remarkable results were achieved with FARO scanner, showing good separability of 
pairwise class even in RGB bands. Surprising is the fact that the cheapest scanner have the best camera. Thorough analysis of the separability coefficients confirms compatibility of the scan data with the spectral curves. For example, the highest separability of pairwise clacit-limestone residual is achieved with GLS1500 (TD value of 1971), whereas FARO and C10 proved incapable of dealing with this (TD value of 1078 and 1523 respectively).

\section{Rock-type Classification}

The rock-type classification for all rock samples was carried out for different wavebands (I, RGB and RGBI) using highest probability method MAXLIKE. Classification results were compared with the prepared specimen truth-images. Table 2 shows Kappa Index of Agreement (KIA) which determines the classification accuracy. KIA is a statistical measure of the significance of difference between an observed agreement of two classifications versus agreement due to random chance (Rosenfield \& Fitzpatric-Lins, 1986).

Table 2. Kappa Index of Agreement (KIA) for classification for different wavebands

\begin{tabular}{|c|c|c|c|}
\hline Bands Scanner & GLS 1500 & FARO & C10 \\
\hline I & 0.2665 & 0.3234 & 0.1031 \\
\hline RGB & 0.4896 & 0.5958 & 0.4324 \\
\hline RGBI & 0.6640 & 0.7073 & 0.5011 \\
\hline
\end{tabular}

The KIA ranges from 0 to 1 . Zero means total agreement from the chance, 1 perfect agreement. The value 0.2665 could be considered as 26.65 percent better agreement than just by a random chance'.Classification completed for only one waveband (I) gives poor result. However, comparison of KIA for this classification allows practically assess the usefulness of each of the scanners. The use of all RGBI bands increases the accuracy of classification. However, the $70 \%$ effectiveness threshold was only achieved by FARO scanner. This is the minimum value to allow a semiautomatic classification. Analysis of the spectral curves and mineral composition of limestone samples makes it clear that differentiation between limestone, dolomitic or silica limestone is extremely difficult. This is caused by traces of dolomite and silica within limestone. In this situation the reasonable solution is to reduce the number of rock-types to four 4 main classes:

- limestone (sample 1/1, 3/2 and 4/2),

- bituminous limestone (sample 3/1 and 4/1),

- calcite (sample K),

- $\quad$ limestone residual (sample 2/1 and 5).

The classification in this case is significantly more accurate. Table 3 includes KIA values for classification carried out in RGBI wavebands. Figure 7 represents comparison of the prepared specimen images with results of classification carried out for the scan data from three scanners 
Table 3. Kappa Index of Agreement (KIA) for classification of main rock-types

\begin{tabular}{|l|l|l|l|}
\hline Scanner & GLS 1500 & FARO & C10 \\
\hline Overall Kappa & 0.73 & 0.77 & 0.67 \\
\hline
\end{tabular}

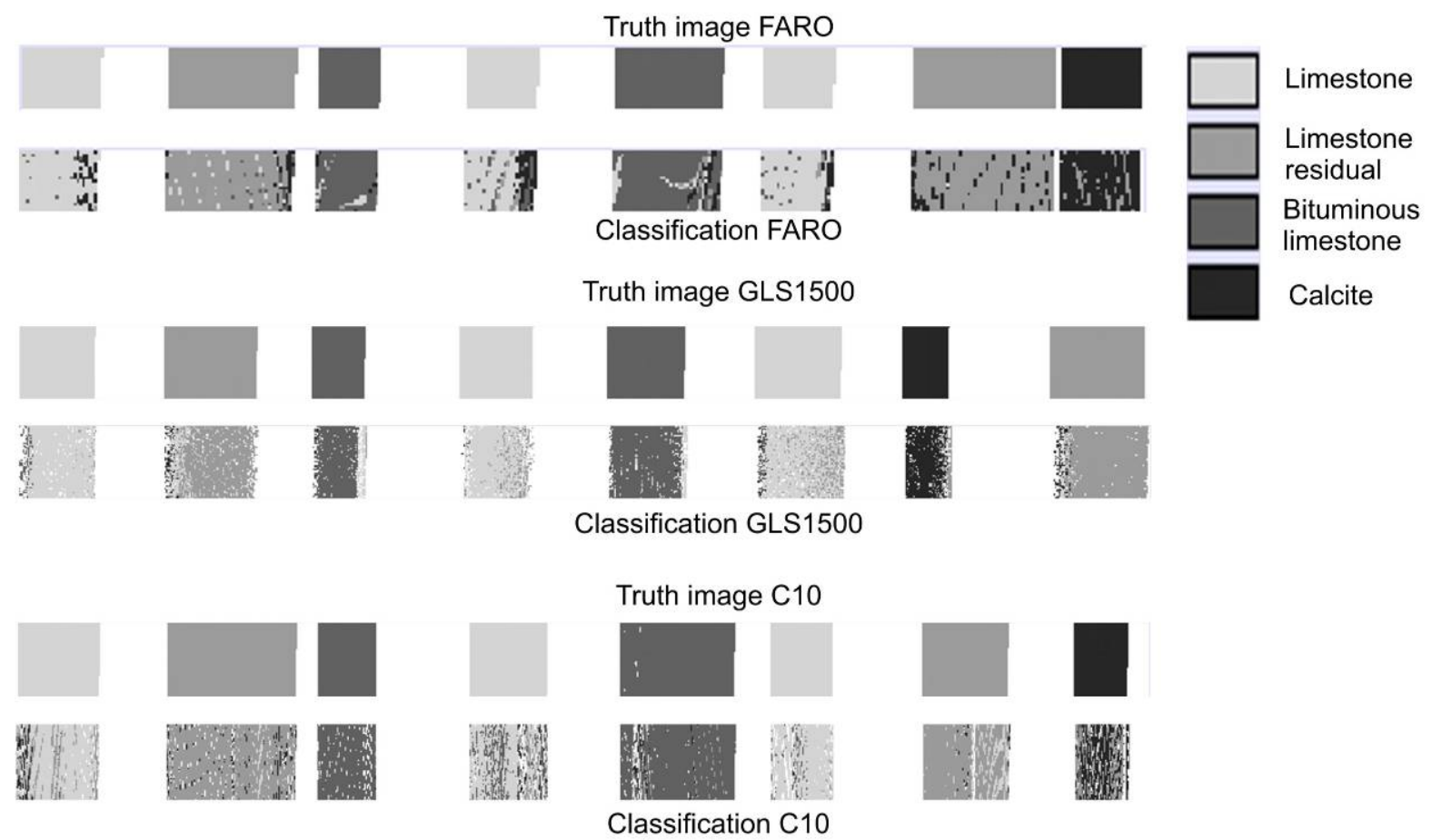

Fig. 7. Rock-type classification for scan data

\section{Discussion and conclusions:}

This paper presents the results of the preliminary tests of the potential for rock identification in Czatkowice Limestone Quarry. The relevant scanning data from scanners operating at different wavelengths was compared. The tests were carried out in laboratory conditions. The samples being examined had nearly flat surfaces positioned perpendicularly in relation to the scanner. The scanning was performed from the same positions in identical light and moisture conditions. Scanning resolution was selected so as to enable examination of the entire sample surface. Therefore, the effect of interference was considerably reduced, thus making it possible to compare the equipments applied.

Based on the results obtained, the following conclusions can be drawn:

1. An analysis made on the samples from the Czatkowice Limestone Quarry demonstrates that correlation exists between the spectrometric measurements and the recorded intensity of the laser beam reflection. It is not a strong correlation but it allows the choice of an optimal scanner.

2. Intensity of the laser beam reflection used as additional band improves the classification results. Significant improvement is achieved where the laser wavelength is in the range at which significant difference of reflectance coefficient of the studied objects occurs. For the Czatkowice Limestone Quarry these are NIR and SWIR bands.

3. Image quality is of significant importance for classification results. If the built-in camera has poor specification, it is advisable to use additional equipment. 
4. The I band from a TLS instrument, whose operation wavelength is in VIS range, cannot provide additional information about the object when the RGB image is used.

The above conclusions and scanner choice procedure presented can be used in any similar case. However, the detailed conclusions as to the effectiveness of rock classification cannot be generalized. Much depends on the mineral composition of limestone (amount of additions) and the accompanying rocks.

In the case being studied, the effectiveness of limestone rock classification with the scan data can exceed $75 \%$, if a suitable instrument is used. The results presented were obtained by laboratory testing without taking into account geometrical factors (e.g. acquisition distance) and environmental factors (e.g. light, moisture conditions). In field conditions, the scanning distance is variable and quarry wall is highly irregular. In this case, it is necessary to consider proper distance corrections and to reduce the influence of laser beam incidence angle. Such corrections can be calculated using geometric data from a cloud of points as reported by (Penasa et al. 2014).

It is not necessary if a terrestrial hyperspectral camera is used. Then, the classification can be based on radiometric data without using the intensity band. The images from hyperspectral camera being classified are superimposed onto three dimensional models from terrestrial laser scanning (Buckley et al. 2013). Using terrestrial hyperspectral cameras is a relatively new trend. More and more such devices can be purchased nowadays, e.g. HySpex camera (Norsk Elektro Optikk) or UHD (Cubert), which can register the entire solar electromagnetic region in narrow bands. The main drawback is a high cost of such devices.

Comparing the spectral curves shown in Figure 2 and Figure 3, a significant influence of rock moisture on reflectance coefficients can be noted. Rock moisture reduces the reflectance, but it does not eliminate the differences between limestone, limestone residual and bituminous limestone in the range $(350-2500 \mathrm{~nm})$. In case of calcite, the difference grows even more. The exception are strong water-related absorption peaks (1400-1600 nm) and (1800-2100). The influence of water on reflectance is more significant in case of porous rock. Given the correlation existing between reflectance and intensity coefficients, similar effect of moisture on the value can be expected, which is acknowledged by (Franceschi et al. 2009). In view of the above, it seems important to choose the scanner which laser wavelength not fall within the ranges (1400-1600 nm) and (1800-2100).

The effect of light conditions was not studied in this paper and will be the subject of future works.

To conclude, the classification of rock can be performed based on the data recorded in identical conditions. This means that scanning data from two point clouds acquired under different environmental conditions cannot be directly compared. This is a limitation of the present method.

\section{Acknowledgement:}

I would like to thank Michał Adamek from TPI Company for his assistance in operating the TLS; Adrian Ochtyra for lending a spectrometer, the Management of Czatkowice Limestone Mine for the permission to access the excavation, and an anonymous reviewer for suggestions which have significantly improved the manuscript. Research was funded by the S-2/233/2014/DS 


\section{References}

Buckley, S. J., Kurz, T. H., Howell, J. A., Schneider, D., (2013). Terrestrial lidar and hyperspectral data fusion products for geological outcrop analysis. Computers \& Geosciences, 54: 249-258. doi: 10.1016/j.cageo.2013.01.018.

Franceschi, M., Teza, G., Preto, N., Pesci, A., Galgaro, A., Girardi, S., (2009). Discrimination between marls and limestones using intensity data from terrestrial laser scanner. ISPRS Journal of Photogrammetry and Remote Sensing, 64(6), 522-528. doi: 10.1016/j.isprsjprs.2009.03.003

Hoefle, B., Pfeifer, N., (2007). Correction of Laser Scanning intensity data: Data and model-driven approaches. International Journal of Photogrammetry and Remote Sensing. 62(6), 415-433. doi: 10.1016/j.isprsjprs.2007.05.008

Maciaszek, J., Ćwiąkała, P. (2010). Badania możliwości zastosowania skanowania laserowego do monitoringu osuwisk zboczy wyrobisk odkrywkowych na przykładzie KWB „,Bełchatów”. Przegląd Górniczy, 66 (6), 52-57. Retrieved from http://www.sitg.pl/starastr/pg/PG 06 2010.pdf

Penasa, L., Franceschi, M., Preto, N., Teza, G., Polito, V., (2014). Integration of intensity textures and local geometry descriptors from Terrestrial Laser Scanning to map chert in outcrops. ISPRS Journal of Photogrammetry and Remote Sensing, 93, 88-97. doi: 10.1016/j.isprsjprs.2014.04.003

Pesci, A., Teza, G.(2008). Effects of surface irregularities on intensity data from laser scanning: an experimental approach. Annals of Geophysics, 51,(5/6). 839-848. doi: 10.4401/ag-4462

Ratcliffe, S., Myers, A. (2006). Laser Scanning in the Open Pit Mining Environment A Comparison with Photogrammetry. I-SiTE Product Development White Paper. June $2006 . \quad$ Retrieved from http://www.gim-international.com/download/whitepaper uploadfile 2.pdf

Richards, J.A., (1993). Remote Sensing Digital Image Analysis (New York: SpringerVerlag) Chapter 10.

Rosenfield, G.H., and K. Fitzpatric-Lins, (1986). A Coefficient of Agreement as a Measure of Thematic Classification Accuracy. Photogrammetric Engineering and Remote Sensing, 52 (2). 223-227

Soudarissanane, S., Lindenbergh, R, Menenti, M., Teunissen P., (2009). Incidence angle influence on the quality of terrestrial laser scanning points. Laser scanning 2009, IAPRS, XXXVIII, (Part 3 W8) 183-188. Retrieved from: http://www.isprs.org/proceedings/xxxviii/3-w8/papers/183 laserscanning09.pdf

Toś, C., Wolski, B., Zielina, L. (2010) Scanning tacheometers. Application of scanning technology at generating of high accuracy models of engineering objects. Kraków: Wydawnictwa Politechniki Krakowskiej. 
Toś, C. (2013). Supervised classification of laser scanning data in the assessment of technical conditions of masonry constructions. Technical transactions. 1-Ś/2013.

Voegtle, T., Schwab, I., Landes, T. (2008). Influence of different materials on the measurements of terrestrial laser scanner. The International Archives of the Photogrammetry, Remote Sensing and Spatial Information Sciences, 37 (B5). 1061-1066.

Retrieved

from http://www.isprs.org/proceedings/XXXVII/congress/5 pdf/182.pdf

Żaczek-Peplińska, J., Falaciński, D. (2011) Evaluation of possibilities to apply laser scanning for assessment of conditions of concrete. Reports on geodesy, 1(2011), 537-544. Retrieved from: yadda.icm.edu.pl/baztech/element/bwmeta1.element.baztech-0a4bd6c9-a49c4916-9da3-761e6e1404ef/c/Zaczek-Peplinska Falacinski.pdf

\section{Authors:}

Cezary Toś ${ }^{1)}$, ctos@pk.edu.pl

1) Department of Land Surveying and Engineering Geology,

Cracow University of Technology, ul Warszawska 24, 30-115 Cracow, Poland 